\title{
A relaçãa entre o complexo industrial e as comunidades científicas: o desafio em tempos de filter bubble
}

The relationship between the industrial complex and the scientific communities: the challenge in filter bubble times

La relación entre el complejo industrial y las comunidades científicas: el desafío en los tiempos de filter bubble

Agradeço à Interface por compor o corpo de debatedores deste artigo mais que necessário por tratar de um assunto imprescindível para profissionais, gestores de saúde e, principalmente, para a população. O rastreamento do câncer de próstata é um ótimo exemplo para se discutir prevenção quaternária, medicalização, cuidado e modos de apropriação do conceito de risco pelo mercado da saúde. No entanto, devido a análises já conhecidas no campo da saúde coletiva em relação a esses temas, tentarei contribuir para o debate a partir de dois eixos: o acúmulo do science studies sobre a relação do complexo industrial com as comunidades científicas e algumas categorias de análise da sociologia da internet, como o filter bubble e o viés da confirmação.

A produção do conhecimento científico vem obedecendo às regras do mercado e, ao mesmo tempo, sustentando cientificamente o próprio mercado. Essa autorregulação produz barreiras para a distribuição do acúmulo de tecnologias para a maioria da população e cria uma forma de se fazer ciência desatrelada às demandas sociais.

Apenas no século XX a hipótese de que existem outras motivações subjacentes, e muitas vezes determinantes, para além do puro interesse intelectual dos cientistas na produção de pesquisas vem sendo investigada e, como era de se esperar, confirmada.

Para Knorr-Cetina ${ }^{1}$, pesquisadora seminal desse campo, existiria sim semelhanças entre a vida social e a vida científica. Apesar de os cientistas sociais não dominarem um determinado tipo de ciência, por exemplo, a biofísica, não quer dizer que não se poderia compreender determinantes que influenciam o resultado das pesquisas biofísicas para além da biologia e da física. O fato de as comunidades científicas serem socialmente construídas corrobora para o entendimento de que, apesar da necessária impessoalidade do cientista no decorrer de suas pesquisas, seus valores e interesses acabam "vazando" no decorrer do processo. O mesmo se aplica para os valores e interesses das próprias comunidades científicas que também se relacionam com outros agrupamentos sociais, não necessariamente de cientistas.

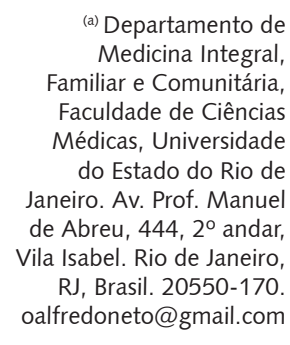

(อ) Interface 
Essas conexões, chamadas por Knorr-Cetina de transepistêmicas, seriam o caminho-chave para se abrir a "caixa-preta" dos estudos sociais sobre a produção do conhecimento.

Tendo-se como precursor Thomas Kuhn, surge um novo campo de estudos sobre a ciência, o science studies (no Brasil, estudos sociais sobre a ciência), que utiliza elementos da história, sociologia e filosofia da ciência. Além da KnorrCetina, despontam nesse campo Harry Collins, Steve Shapin, Andrew Pickering, Ian Hacking e Bruno Latour.

Torna-se importante notar o quanto que o raciocínio científico dentro de um laboratório está imbricado com o raciocínio econômico. Segundo Knorr-Cetina, palavras como "risco", "custos" e "vendas" estão no cotidiano dos cientistas. Alguns exemplos tornam mais evidentes essa relação:

- Objetos científicos podem ser inventados graças à fascinação dos cientistas por uma tecnologia rara e dispendiosa, ou descartados caso não estejam envolvidos com tecnologias de ponta, de altos custos ou da moda.

. A sociedade não seleciona e prioriza os temas que precisam ser pesquisados. Isso geralmente ocorre por meio das demandas das agências financiadoras, que possuem muitos conflitos de interesses não declarados e pouca transparência em relação aos processos decisórios.

Para a sociologia do conhecimento científico, a pouca transparência das etapas científicas e a seleção de quais pesquisas, e com qual linguagem, serão informadas ao grande público pela mídia levam ao encantamento popular da ciência como espaço ilusório para gênios privilegiados. A preocupação é quando essa seleção e influência ficam a cargo das indústrias na saúde².

Segundo Goldacre ${ }^{3}$, em algumas ocasiões há o interesse de publicar apenas uma parte da pesquisa, sendo essa parte aquela que possui principalmente maior inclinação comercial, por meio de acordos entre mídias e companhias farmacêuticas. Além disso, quanto mais famoso se torna o cientista, menos preocupações éticas serão destinadas para avaliar as etapas e as relações de interesse de suas pesquisas.

Em 2002, a Universidade da Califórnia montou uma biblioteca virtual, a Industry Documents Library, onde há milhões de documentos das indústrias de tabaco, farmacêutica e química. A Legacy Tobacco Documents Library possui 14 milhões de documentos das indústrias de tabaco sobre estratégias de venda, marketing e campanhas desde antes da década de $1950^{(b)}$. Esse imenso arquivo de dados vem possibilitando a compreensão de quais artimanhas eram escolhidas para não se perder mercado diante do resultado de grandes estudos epidemiológicos relacionando cigarro a doenças cardiovasculares e cânceres.

A falta de informações ou seu excesso geram dúvidas no consumidor. É justamente a dúvida que leva a ações precipitadas. As indústrias de tabaco já sabiam dos malefícios do cigarro muito antes da população. A estratégia foi a criação de um grupo de cientistas e jornalistas renomados com o objetivo de produzir argumentos contrários e pesquisas falsas, no intuito de gerar dúvidas na população em relação à veracidade dos estudos relacionando cigarro a doenças e mortalidade. A contratação desses profissionais se dava pelo Tobacco Institute, um órgão de produção científica e planejamento de marketing, e pelo The Advancement of Sound Science Coalition, este último criado em resposta após a Enviromental Protection Agency, agência americana de proteção ao meioambiente, ter iniciado uma forte campanha sobre os malefícios dos riscos ao fumante passivo.

(b) Disponibilizadas em: http://legacy.library.ucsf. edu/. 
Outra estratégia se dava por meio do financiamento a ONGs que lutavam a favor da liberdade individual. A britânica Freedom Organization for the Right to Enjoy Smoking Tobacco foi criada e patrocinada pela British Tobacco Advisory Council, órgão que reúne as indústrias de tabaco do Reino Unido 4,5 .

Trago a discussão desse campo e exemplos de pesquisas para encorajar pesquisadores brasileiros interessados em conhecer as estratégias das indústrias farmacêuticas e de tecnologia diagnóstica para a América do Sul e o Brasil.

Outro ponto que trago para o debate é o conceito de filter bubble e o viés da confirmação.

Algoritmos criados por sites de busca, principalmente o Google, e por redes sociais, especialmente o Facebook, permitiram que a aldeia global, contraponto de McLuhan à cultura de massas, fosse reduzida a uma bolha com sujeitos que defendem, pensam e gostam dos mesmos temas e produtos político-culturais. Tais filtros criados na arquitetura de software possuem o objetivo de facilitar a venda para anunciantes por nichos do mercado, dependendo do posicionamento político ou gosto estético do internauta. Esse mecanismo produz uma identidade de pertencimento e conforto, pois cada vez menos as pessoas são expostas a pontos de vista conflitantes aos seus e, cada vez mais, amigos e mecanismos de busca reforçam suas ideias preexistentes ${ }^{6}$.

Já o viés da confirmação é a capacidade de acreditar e interpretar apenas o que reforça essas ideias preexistentes, independente da evidência argumentativa, legal ou científica expressa no texto, no áudio ou no vídeo mostrando justamente o contrário. Inicialmente estudada pela psicologia na década de 1950 entre torcedores de times de futebol americano distintos, ou seja, uma população culturalmente polarizada, o viés da confirmação vem sendo pesquisado no campo da sociologia da internet. A hipótese é que o filter bubble amplia o viés da confirmação, expandindo a polarização e diminuindo a capacidade de diálogo $0^{6,7}$.

Apesar de existirem evidências epidemiológicas para o não rastreio da próstata em homens assintomáticos, se a interpretação de análises como risco absoluto e relativo, além da identificação de vieses nas etapas de pesquisas, é um desafio até para médicos, quanto mais para a população em geral de um país com acentuada desigualdade de acesso a uma educação de qualidade. Segundo Camargo $\mathrm{Jr}^{8}$, o fato de as pessoas conhecerem as medidas preventivas não quer dizer que saibam na prática, por exemplo, o conceito de probabilidade.

Além disso, a ilusão de que uma sociedade se beneficiaria se cada um "tomasse conta" da sua saúde desestabiliza o princípio de equidade, ignora dados epidemiológicos e socioeconômicos e permite que demandas de saúde sejam amplamente distorcidas pelo complexo médico-industrial, amparados pela mídia.

Após a leitura do artigo torna-se tentador que futuras análises se debrucem, por exemplo, nas relações do Instituto Lado a Lado Pela Vida e das sociedades de urologia com o complexo médicoindustrial, por meio da análise de filter bubble e do viés da confirmação em postagens e comentários nas redes sociais.

\section{Referências}

1. Knorr-Cetina KD. Scientific communities or transepistemic arenas of research? a critique of quasi-economic models of science. Soc Stud Sci. 1982; 12(1):101-30.

2. Miguelote VRS, Camargo Jr KR. Indústria do conhecimento: uma poderosa engrenagem. Rev Saude Publica. 2010; 44(1):190-6.

3. Goldacre B. Bad science. London: Harper Perennial; 2009. 
4. Michaelis D. Doubt is their product: how industry's assault on science threatens your health. Oxford: Oxford University Press; 2008.

5. Oreskes N, Conway EM. Merchants of doubt: how a handful of scientists obscured the truth os issues from tobacco smoke to global warming. New York: Bloomsbury Press; 2010.

6. Pariser E. O filtro invisível: o que a internet está escondendo de você. Rio de Janeiro: Zahar; 2012.

7. Nikolov D, Oliveira DFM, Flammini A, Menczer F. Measuring online social bubbles. PeerJ Comp Sci. 2015; 1:38.

8. Camargo Júnior KR. Entrevista. In: ABIA. Associação Brasileira Interdisciplinar de AIDS: 25 anos. Rio de Janeiro: Boletim ABIA; 2012. v. 58. 